\title{
Primary Hypothyroidism and Breast Cancer: Clinical and Pathological Risk Reduction Correlates from a Case Control Study
}

\author{
Sidra Khalid ${ }^{1 *}$, Hamed Daw ${ }^{2}$, Swati Thakur ${ }^{3}$ and \\ Aleck Hercbergs ${ }^{4}$ \\ ${ }^{1}$ Department of Internal Medicine, Cleveland Clinic - \\ Fairview Hospital, USA \\ ${ }^{2}$ Department of Hematology and Oncology, Cleveland \\ Clinic - Fairview Hospital, USA \\ ${ }^{3}$ Department of Internal Medicine, Cleveland Clinic, USA \\ ${ }^{4}$ Department of Oncology, Cleveland Clinic, USA \\ *Corresponding author: Khalid S, Department of \\ Internal Medicine, Cleveland Clinic - Fairview Hospital, \\ USA
}

Received: March 02, 2017; Accepted: May 15, 2017; Published: May 26, 2017

\begin{abstract}
Background: A putative link between thyroid dysfunction and the natural history of breast cancer is controversial, but numerous studies suggest that primary hypothyroidism is associated with a biologically less aggressive and clinically more indolent disease.Hence, in cancer patients with primary hypothyroidism, modification of the daily dose of L-thyroxine might potentially affect the course and prognosis of active breast cancer.
\end{abstract}

Methods: 2,044 charts were reviewed in a hospital-based retrospective case-control study of 159 female patients with AJCC stage 1-4 invasive breast cancer over a 10-year period. 68 cases of invasive breast cancer with primary hypothyroidism were compared to 91 matched controls. The differences in age of diagnosis, survival and clinic opathological variables were analyzed for the two groups.

Results: Compared to euthyroid patients those with hypothyroidism were diagnosed with breast cancer 4.7years later (mean age at diagnosis 68.12 vs. 63.44 years, $p<0.035$ ). The primary tumor measured $<1 \mathrm{~cm}$ in $27.4 \%$ of hypothyroid vs. $11.4 \%$ of euthyroid patients, $p<0.047$. Hypothyroid patients were less likely to have lymph node involvement $(21.6$ vs. $40.5, p<0.28)$ and more likely to have low $S$ phase fraction $(79.4$ vs. $60.4, p<0.21)$. There was insufficient data for thyroid function correlation and survival analysis.

Conclusion: Therefore, in women with L-thyroxine supplemented primary hypothyroidism, breast cancer is diagnosed over a 4 subclinical years later age than in a euthyroid cohort and is a less aggressive disease. Prospective clinical and thyroid function correlative studies are indicated to validate these findings.

Keywords: Breast cancer; Hypothyroidism; Euthyroid; Thyroxine

\section{Abbreviations}

BC: breast cancer; HYP: Hypothyroidism; L-thy: L-thyroxine

\section{Introduction}

The controversy concerning a putative link between thyroid dysfunction and the natural history of Breast Cancer (BC) is ongoing, but only recently a growing body of evidence provided support for the permissive and proliferative effect of L-thyroxine (L-thy) in this and other malignancies. Data from preclinical studies have shown the proliferative effects of thyroxine. The potential for thyroid hormone levels to impact differentially on prognosis in cancer is of interest, especially since the dose of supplemental L-thy in cancer patients with primary Hypothyroidism (HYP) can be easily adjusted, which could impact the course and prognosis of an individual with active cancer. Hence, we have proceeded with a retrospective study, reviewing the charts of 2,044 patients to further delineate the link between HYP and $\mathrm{BC}$.

\section{Materials and Methods}

This was a hospital based retrospective case-control study. 2,044 electronic and paper charts were reviewed from which 159 female patients had AJCC stage 1-4 invasive BC patients (infiltrating ductal (129), lobular (19) carcinoma- the majority) over 10 years.68 cases of invasive BC had primary HYP. Primary HYP was defined as patients on L-thy supplementation prescribed by an endocrinologist or internist. The 68 cases were compared to 91 matched controls. The patients were matched for $\mathrm{BC}$ stage, baseline socio-demographics, and history of estrogen replacement, familial BC, pregnancy, body mass index, and menarche. Differences in age of diagnosis, survival and clinic-pathological variables were analyzed. Thyroid hormone blood levels and L-thy dosage were generally unavailable. The statistical analysis was done on the SAS 9.0 statistical software program and the Chi-square, fisher's exact test and the Wilcoxon 2 sample tests were utilized.

\section{Results}

Compared to euthyroid patients those with HYP were diagnosed with BC 4.7 years later (mean age at diagnosis 68.12 vs. 63.44 years, $\mathrm{p}<0.035$ ). The primary tumor measured less than $1 \mathrm{~cm}$ in $27.4 \%$ of HYP vs. $11.4 \%$ of euthyroid patients, $\mathrm{p}<0.047$. HYP patients were also less likely to have lymph node involvement (21.6 vs. $40.5, \mathrm{p}$
Annals Thyroid Res - Volume 3 Issue 1 - 2017

Submit your Manuscript | www.austinpublishing group.com

Khalid et al. (C) All rights are reserved
Citation: Khalid S, Daw H, Thakur S and Hercbergs A. Primary Hypothyroidism and Breast Cancer: Clinical and Pathological Risk Reduction Correlates from a Case Control Study. Annals Thyroid Res. 2017; 3(1): 102-104. 
Table 1: Breast cancer characteristics and comparison in hypothyroid and euthyroid patients.

\begin{tabular}{|c|c|c|c|c|c|c|c|}
\hline & & \multirow[b]{2}{*}{ Total } & \multicolumn{2}{|c|}{ Hypothyroid } & \multicolumn{2}{|c|}{ Euthyroid } & \multirow{2}{*}{\begin{tabular}{|c|}
$\mathbf{P}$ \\
Value
\end{tabular}} \\
\hline & & & $\mathrm{N}$ & (\%) & None & (\%) & \\
\hline \multirow{7}{*}{$\begin{array}{c}\text { Breast Cancer } \\
\text { Type }\end{array}$} & & & & & & & $0.33 F$ \\
\hline & Inf ductal ca & 129 & 52 & 78.8 & 77 & 82.8 & \\
\hline & Inf lobular ca & 19 & 11 & 16.7 & 8 & 8.6 & \\
\hline & Adenocarcinoma & 5 & 1 & 1.5 & 4 & 4.3 & \\
\hline & Tubular adeno & 2 & 0 & 0 & 2 & 2.2 & \\
\hline & Mucinous adeno & 3 & 2 & 3 & 1 & 1.08 & \\
\hline & Medullary ca & 1 & 0 & 0 & 1 & 1.08 & \\
\hline \multirow{4}{*}{ Grade } & & & & & & & 0.96 \\
\hline & Well diff & 20 & 9 & 18.8 & 11 & 20.4 & \\
\hline & Mod diff & 41 & 20 & 41.7 & 21 & 38.9 & \\
\hline & Poor diff & 41 & 19 & 39.6 & 22 & 40.7 & \\
\hline \multirow{6}{*}{ Stage } & & & & & & & $0.38 \mathrm{~F}$ \\
\hline & 0 & 1 & 1 & 1.6 & 0 & 0 & \\
\hline & 1 & 62 & 26 & 41.3 & 36 & 40.5 & \\
\hline & 2 & 62 & 28 & 44.4 & 34 & 38.2 & \\
\hline & 3 & 17 & 4 & 6.4 & 13 & 14.6 & \\
\hline & 4 & 10 & 4 & 6.4 & 6 & 6.7 & \\
\hline \multirow{3}{*}{ Lymph Node } & & & & & & & 0.28 \\
\hline & -ve & 92 & 39 & 68.4 & 53 & 59.6 & \\
\hline & $+v e$ & 54 & 18 & 31.6 & 36 & 40.5 & \\
\hline \multirow{3}{*}{ ER } & & & & & & & 0.81 \\
\hline & -ve & 33 & 13 & 20.6 & 20 & 22.2 & \\
\hline & $+v e$ & 120 & 50 & 79.4 & 70 & 77.8 & \\
\hline \multirow{3}{*}{ PR } & & & & & & & 0.36 \\
\hline & -ve & 65 & 24 & 38.1 & 41 & 45.6 & \\
\hline & + ve & 88 & 39 & 61.9 & 49 & 54.4 & \\
\hline \multirow{3}{*}{ HER-2 } & & & & & & & 0.49 \\
\hline & -ve & 110 & 50 & 87.7 & 60 & 83.3 & \\
\hline & + ve & 19 & 7 & 12.3 & 12 & 16.7 & \\
\hline \multirow{4}{*}{ S phase } & & & & & & & $0.21 \mathrm{~F}$ \\
\hline & 1 & 59 & 27 & 79.4 & 32 & 60.4 & \\
\hline & 2 & 5 & 1 & 2.9 & 4 & 7.6 & \\
\hline & 3 & 23 & 6 & 17.7 & 17 & 32.1 & \\
\hline \multirow{3}{*}{$U / L$ vs $B / L$} & & & & & & & $0.70 \mathrm{~F}$ \\
\hline & $U / L$ & 151 & 64 & 97 & 87 & 94.6 & \\
\hline & $B / L$ & 7 & 2 & 3 & 5 & 5.4 & \\
\hline \multirow{3}{*}{ Size $=$ or $>1$} & & & & & & & 0.047 \\
\hline & 0 & 25 & 15 & 23.4 & 10 & 11.4 & \\
\hline & 1 & 127 & 49 & 76.6 & 78 & 88.6 & \\
\hline \multirow{3}{*}{ Size $=$ or $>2$} & & & & & & & 0.82 \\
\hline & 0 & 72 & 31 & 48.4 & 41 & 46.6 & \\
\hline & 1 & 80 & 33 & 51.6 & 47 & 53.4 & \\
\hline \multirow{3}{*}{ Size $=$ or $>3$} & & & & & & & 0.7 \\
\hline & 0 & 114 & 47 & 73.4 & 67 & 76.1 & \\
\hline & 1 & 38 & 17 & 26.6 & 21 & 23.9 & \\
\hline
\end{tabular}

$<0.28$ ) and more likely to have low $\mathrm{S}$ phase fraction (79.4 vs. $60.4, \mathrm{p}$ $<0.21)$. No statistical significance was noticed between data for the hormonal receptors ER, PR and Her-2 (Table 1).

\section{Discussion}

It has been shown that $\mathrm{T} 4$ in its physiological free hormone concentrations stimulates proliferation of a variety of cancer cells in vitro $[1,2]$. The cancer cell genes regulated by $\mathrm{T} 4$ control cellular proliferation, defense pathways and angiogenesis [1,3]. A mechanism for thyroxine modulated angiogenesis and anti-apoptosis has been reported by Bergh, $\mathrm{J}$ et al. wherein $\mathrm{T} 4$ binds to a cell surface receptor, integrin $a v \beta[3,4]$. Through this receptor the T4 regulates trafficking of specific proteins (ERa, TR, p53) and via signal transducing kinases influences transcription of cancer-relevant genes. Likewise, T4 stimulates angiogenesis by the induction of transcription of vascular growth factor genes, such as fibroblast growth factor and vascular endothelial growth factor; genes for hypoxia inducible factor and matrix metalloproteinase-9. However, T3 has low affinity for the cell membrane receptor, thereby it is not anti-apoptotic [5].

This retrospective case control study identifies the significant clinicopathological differences between the HYP cohort and controls. These differences are consistent with a less aggressive clinical phenotype in the HYP cohort. The study results for diagnosis of $\mathrm{BC}$ at an older age in HYP patients are further supported by other retrospective studies. Cristofanilli, $\mathrm{M}$ et al. performed a retrospective study in which 78 out of 1136 women had primary BC with HYP. They were older at the time of diagnosis (58.8 years vs. 51.1 years; $\mathrm{P}$ $<0.001)$, were more likely to have localized disease $(95.0 \%$ vs. $85.9 \%$ clinical $\mathrm{T} 1$ or $\mathrm{T} 2$ disease, respectively; $\mathrm{P}=0.025)$, and were more likely to have no pathologic lymph node involvement $(62.8 \%$ vs. $54.4 \%$; $\mathrm{P}$ $=0.15)$. In the BC group, HYP patients were $7(\mathrm{p}<0.001), 7$ and 6 years older $(p<0.035)$ at diagnosis in three studies [6-8]. BC incidence was significantly lower in the HYP group $(p<0.003)$. Tumors were also smaller in the HYP group $(\mathrm{p}<0.047)$ and were more likely to be localized. Euthyroid patients were also more likely to have metastatic disease. Hence, it was concluded that primary HYP was associated with a reduced risk for primary $\mathrm{BC}$ and a less aggressive invasive disease (Table 2).

Various reports and analyses suggest that HYP increases response rates to chemo- and/or radiation therapy $[9,10]$. Additionally, the effect of a HYP state is associated with increased survival in multiple cancers. The first report of an association with thyroid supplementation and BC was in 1976.From a population of 314 women with metastatic BC, 9 of $11(82 \%)$ women surviving over 5 years were found to be HYP [11]. In a case-control study of lung cancer, patients with lung cancer and a history of $\mathrm{TH}$ requirement (thyroid hormone replacement) had a mean age at diagnosis of 73 years vs. 64 years for euthyroid patients $(\mathrm{p}=0.0006)$. The TH group median survival was 14.5 months vs. 11.1 months $(\mathrm{p}=0.014) 12$. In contrast, in $176 \mathrm{BC}$ patients who had taken L-thy for $>2$ years within 10 years of developing $\mathrm{BC}$ had a greater relapse rate when compared with controls at 3 years ( $43.9 \%$ vs. $18.8 \%, p=0.002)$ [10]. Their tumors were also larger $(\mathrm{p}=0.01)$. Likewise, the incidence of $\mathrm{BC}$ is higher in patients on thyroid supplementation by $12.13 \%$, when compared to the control group (6.2\%) [12]. Additionally, thyroid function and cancer risk was evaluated through a prospective trial including 29,691 people. It concluded that hyperthyroidism leads to an increased risk of prostate and lung cancer. While, HYP does not seen to be associated 
Table 2: Comparison of euthyroid and hypothyroid patients and age of diagnosis of breast cancer.

\begin{tabular}{|c|c|c|c|c|c|c|c|c|c|c|}
\hline \multirow{3}{*}{ Age of Diagnosis } & Hypothyroidism & $n$ & mean & sd & $\min$ & P25 & median & P75 & $\max$ & Pvalue* \\
\hline & No & 93 & 63.44 & 13.7 & 32 & 56 & 65 & 73 & 93 & $0.035^{\star *}$ \\
\hline & Yes & 66 & 68.12 & 13.91 & 35 & 59 & 70 & 79 & 94 & \\
\hline
\end{tabular}

with cancer risk [13]. Similarly, a research study in Denmark followed 60,000 women with a HYP and 80,000 women with hyperthyroidism from 1978-2013. They concluded that hyperthyroidism was associated with a slightly increased risk of breast cancer when compared to the general population (standardized incidence ration of 1.13, 95\% CI: 1.08-1.19) [14]. In a prospective cohort study, from 318 subjects, higher FT4 levels were associated with a higher risk of solid cancers, including breast cancer [15]. Likewise, medically inducing hypothyroxinemia by using methimazole or T3 has shown survival benefit in patients with terminal solid cancers. $83 \%$ of patients (19 of 23) exceeded the $20 \%$ expected 1 -year survival, which highlights the value of inducing hypothyroxinemia in cancer patients [16].

One possible mechanism for the later mean age of diagnosis of cancers is that subclinical hypothyroidism may take a number of years to evolve (as in Hashimoto's thyroiditis) to a clinical requirement for $\mathrm{TH}$ supplementation, which could then elicit progression of a preexisting, indolent, subclinical cancer [17]. In this regard the potential for altered thyroid hormone levels to impact differentially on prognosis in cancer is of interest since the dose of supplemental L-thy in cancer patients with primary HYP is easily subject to adjustment. The potential for altering the course and prognosis of an individual with active cancer may therefore depends on appropriate minimally pro-oncogenic daily L-thy dosage or even by the less pro-oncogenic L-triiodothyronine.

The major weakness of this retrospective study is the lack of blood thyroid function studies possibly in view of the long elapsed time from diagnosis and initiation of L-thy supplementation (several years) and its management by a primary care physician. These data could not be obtained due to multiple logistical issues. Nonetheless patients identified as HYP in this study clearly constitute a separate cohort with less aggressive pathological and clinical characteristics. These data should be interpreted with caution even though largescale studies suggest that almost $20 \%$ of individuals on L-thy supplementation may be chemically HYP.

\section{Conclusion}

This study suggests that in women with L-thy supplemented primary HYP, BC is diagnosed over 4 'asymptomatic' years later than in a euthyroid cohort and have a less aggressive disease. Individuals with primary BC categorized /identified as HYP by virtue of their L-thy supplementation for previously diagnosed chemical HYP may constitute a biologically distinct population with a more favorable and less aggressive natural history. Prospective clinical and thyroid function correlative studies are indicated to validate these findings.

\section{References}

1. Guernsey DL, Ong A, Borek C. Thyroid hormone modulation of X-ray-induced in vitro neoplastic transformation. Nature (London). 1980; 288: 591-592.
2. Borek C, Guernsey DL, Ong A, Edelman IS. Critical role playedbyn thyroid hormone in induction of neoplastic transformation by chemical carcinogens in tissue culture. Proc Natl Acad Sci USA. 1983; 80: 5749-5752.

3. Feng $X$, Jiang $Y$, Meltzer $P$, Yen PM. Thyroid hormone regulation of hepatic genes in vivo detected by complementary DNA microarray. Mol Endocrinol. 2000; 14: 947-955.

4. Bergh JJ, Lin HY, Lansing L, Mohamed SN, Davis FB, Mousa S, et al. Integrin avb3 contains a cell surface receptor site for thyroid hormone that is linked to activation of MAPK and induction of angiogenesis. Endocrinology. 2005; 146: 2864-2871.

5. Hercbergs A, Davis $P$, Lin $H$, Mousa S. Possible contributions of thyroid hormone replacement to specific behaviors of cancer. Biomedicine \& Pharmacotherapy. 2016; 84: 655-659.

6. Cristofanilli M, Yamamura Y, Kau SW, Bevers T, Strom S, Patangan M, et al. Thyroid hormone and breast carcinoma. Primary hypothyroidism is associated with a reduced incidence of primary breast carcinoma. Cancer. 2005; 103: 1122-1128.

7. Backwinkel K, Jackson A. Some features of breast cancer and thyroid deficiency. Cancer. 1964; 17: 1174-1176.

8. Hercbergs $\mathrm{AH}$, Daw $\mathrm{H}$, Thakur S. Primary Hypothyroidism and Breast Cancer:-Clinical and Pathological Risk Reduction Correlates from a Case Control Study. Proceedings of the $80^{\text {th }}$ Annual Meeting of the ATA, Palm Beach, Florida. 2009.

9. Hercbergs $\mathrm{A}$. The thyroid gland as an intrinsic biologic response -modifier in advanced neoplasia-a novel paradigm. In Vivo. 1996; 10: 245-247.

10. Jack RF, et al. Thyroid Hormone -A modifier of the natural history of breast cancer Abstract \#738 AACR. 1983.

11. Kapdi CC, Wolfe JN, Shapiro S. Breast cancer. Relationship to thyroid supplements for hypothyroidism. JAMA. 1976; 236: 1124-1127.

12. Hercbergs A, Mason J, Reddy C. Thyroid hormones and Lung Cancer: Primary hypothyroidism is prognostically significant for survival in lung cancer. 95th Annual Meeting, AACR. 2004.

13. Hellevik A, Asvold B, Bjoro T, Romundstad PR, Nilsen TI, Vatten LJ. Thyroid function and cancer risk: A prospective population study. Cancer Epidemiol Biomarkers Prev. 2009; 18: 570-574.

14. Sogaard M, Farkas DK, Ehrenstein V, Jorgensen JO, Dekkers OM, Sorensen HT. Hypothyroidism and hyperthyroidism and breast cancer risk: a nationwide cohort study. Eur J Endocrinol. 2016; 174: 409-414.

15. Khan SR, Chaker L, Ruiter R, Aerts JG, Hofman A, Dehghan A, et al. Thyroid Function and Cancer Risk: The Rotterdam Study. J Clin Endocrinol Metab. 2016; 101: 5030-5036.

16. Hercbergs A, Johnson RE, Ashur-Fabian O, Garfield DH, Davis PJ. Medically induced euthyroid hypothyroxinemia may extend survival in compassionate need cancer patients: an observational study. Oncologist. 2015; 20: 72-76.

17. Huber G, Staub JJ, Meier C, Mitrache C, Guglielmetti M, Huber P, et al Prospective study of the spontaneous course of subclinical hypothyroidism: prognostic value of thyrotropin, thyroid reserve, and thyroid antibodies. J Clin Endocrinol Metab. 2002; 87: 3221-226. 